\title{
Comparison of total phenol content and antioxidant activity of herbal infusions with added Stevia reabaudiana Bertoni
}

\author{
Ma Claudia CASTAÑEDA-SAUCEDO ${ }^{1}$ (D), Jessica del Pilar RAMÍREZ-ANAYA ${ }^{1}$ (D), Ernesto TAPIA-CAMPOS ${ }^{2 *}$ (D), \\ Elvia Guadalupe DIAZ-OCHOA ${ }^{1}$
}

\begin{abstract}
Antioxidant capacity (AC) was determined by the ABTS method and DPPH, and total phenol content (TPC) in dehydrated plant material, in infusions and in residues (plant material after preparing the infusion) of white, black, red, green, spearmint, stevia, lemon grass and chamomile teas to which stevia leaves were added or not added; addition of processed stevia powder was also tested. Three independent experiments were set up: with dehydrated plant material, with infusions and with residues. For the case of dehydrated plant material, white tea had the highest TPC (10813.5 mg GAE/100g) and AC by the ABTS method $(1183.3 \mu \mathrm{M} \mathrm{TE} / \mathrm{g})$ and DPPH method $(1525.0 \mu \mathrm{M} \mathrm{TE} / \mathrm{g})$. In infusions, black tea had higher TPC (180.82 $\mu \mathrm{g} \mathrm{GAE} / \mathrm{ml})$ and AC by the methods ABTS and DPPH (0.6114 and $2.5983 \mu \mathrm{M} \mathrm{TE} / \mathrm{ml}$, respectively). In residues, TPC was higher in white tea, while green tea had the highest AC values. AC of dehydrated plant material increased when stevia leaves were added, according to the DPPH and ABTS methods, but not in residues by ABTS. Addition of stevia leaves in infusions increased AC in white, lemon grass, chamomile and stevia teas by the ABTS method and in spearmint, black, red, and green teas with the DPPH method.
\end{abstract}

Keywords: Camellia sinensis; Matricaria chamomilla; Cymbopogon citratus and Mentha spicata.

Practical Application: Addition of stevia leaves in most of the herbal infusions tested increased TPC and AC by DPPH.

\section{Introduction}

An infusion is a beverage obtained from parts (dry leaves, flowers and fruits) of the shoot of several herbs or aromatic plants. Worldwide, most of the infusions are prepared from two types of manufactured teas: black and green teas (Konieczynski et al., 2017), which are obtained from Camellia sinensis leaves, as are white and red teas. However, the growing season, geographic region and methods of fermentation create much variation in the composition and characteristics of the tea (Zhao et al., 2011) in addition to the variation associated with different stages of maturity of the leaves (Kosińska \& Andlauer, 2014). Based on the method of fermentation, teas have been classified as non-fermented (white and green tea), semi-fermented (red tea) and fermented (black tea) (Camargo et al., 2016). Today, consumption of infusions has increased because of their beneficial properties, which are attributed to the presence of phenolic compounds (Cleverdon et al., 2018). These compounds have higher antioxidant capacity than fruits and vegetables and are even more potent than vitamin C, E and carotenoids (Wiseman et al., 1997). Because of these characteristics, teas are often used as remedies to cure diverse organic disorders. In this respect, Hernández-Saavedra et al. (2013) report that herbal infusions can help reduce obesity, insulin intolerance and systemic inflammation. In addition, dehydrated stevia leaves can be added to infusions to improve their characteristics (Shevchenko et al., 2013). Because stevia has therapeutic values such as antioxidant, antimicrobials, antidiabetics, antihypertensive, cardiotonic; also; it has stevioside and rebaudioside, which give it an intense sweet flavor; it is good source of protein, crude fibre, minerals and amino acids (Joseph \& George, 2019; Ahmed \& Mukta, 2017). Processed stevia is up to 200-300 times sweeter than sucrose (Ghaheri et al., 2018), it is considered the best sugar substitute (Joseph \& George, 2019). Although stevia extracts are being used only as sweeteners, aqueous extract of the dehydrated leaves have numerous functional properties (Ahmed \& Mukta, 2017). It is believed that commercial infusions sweetened with stevia are a viable option that can contribute to the health of people who consume them. The aim of this study was to compare TPC and AC in dehydrated plant material, infusions and residues of white, black, red, green, spearmint, stevia, lemon grass and chamomile teas with or not addition stevia leaves and processed stevia.

\section{Materials and methods}

The study was conducted in the plant physiology laboratory of the CUSUR-UDG. Eight different plant materials were used: white, black, red and green tea (Camellia sinensis), spearmint (Mentha spicata), lemon grass (Cymbopogon citratus), chamomile (Matricaria chamomilla) and Stevia rebaudiana B. Three independent experiments were set up: 1) plant material before infusion, 2) infusion, and 3) plant material after infusion (considered

${ }^{1}$ Laboratory of Plant Physiology, Centro Universitario del Sur - CUSUR, Universidad de Guadalajara - UDG, Cd. Guzmán, Jalisco, México

${ }^{2}$ Centro de Investigación y Asistencia en Tecnología y diseño del Estado de Jalisco - CIATEJ, Guadalajara, Jalisco, México

*Corresponding author: etapia@ciatej.mx 
residue). In each experiment, a two-factorial analysis was used in which one factor was the plant material (white, black, red and green tea, spearmint, lemon grass, chamomile and stevia); the other factor was the addition of $0.25 \mathrm{~g}$ dehydrated ground stevia leaves (ASL), commercial processed powdered stevia (PS) (Member's Mark) and without stevia (WSL). In experiments 1 and 3, only ASL and WSL were considered, and in experiment 2 ASL, PS and WSL were studied. The commercial brand of chamomile, spearmint, green tea and lemon grass was Vitte ${ }^{\circledR}$ and black, white and red tea were Euro te ${ }^{\circledR}$. Stevia leaves were produced in a greenhouse, dried in an oven at $50{ }^{\circ} \mathrm{C}\left(\right.$ Binder $^{\circledR}$ series FD) and ground in a mill (KRUPS GX4100).

\subsection{Preparation of infusions}

To prepare the infusions, the technique described by Muñoz-Velázquez et al. (2012) was used with slight modifications. One gram of each of the eight plant materials were used (White, black, red and green teas, spearmint, lemon grass, chamomile and stevia); each infusion was replicated four times. The plant materials were sweetened by adding 1 ) one envelope of processed powdered stevia, 2) $0.25 \mathrm{~g}$ dried ground stevia leaves and 3) no sweetener. Filter paper was used to wrap the plant material and place it in the infuser; $250 \mathrm{ml}$ water at $90{ }^{\circ} \mathrm{C}$ was poured into a cup and the infuser was introduced and left for $5 \mathrm{~min}$. After this time the infuser was withdrawn and left to drain on a support for $5 \mathrm{~min}$. The plant material was then taken out of the infusers, and both the infusion and the residues were left to cool to room temperature. Later, $45 \mathrm{ml}$ of the infusion of each replication was stored at $-20^{\circ} \mathrm{C}$ until quantification. In the same way, the plant residues were stored at $-20^{\circ} \mathrm{C}$ until extraction and later quantification of total phenol content and antioxidant capacity.

\subsection{Sample extraction}

Sample extractions were carried out following Saura-Calixto, (1998), with some modifications. Of the eight dehydrated plant materials, ASL and WSL, $0.5 \mathrm{~g}$ were used, and $2 \mathrm{~g}$ of the moist plant material after use in the infusion (residue), which is equivalent to about 0.5 dehydrated plant material, was adjusted to real weight at calculation. Both dehydrated and moist (residues) plant material ASL and WSL were placed in a $50 \mathrm{ml}$ plastic Corning tube with a stopper. Each material was replicated four times. The substrates were weighed on a scale (Santorius Te2145), and $4 \mathrm{ml}$ acidified ( $\mathrm{pH}$ 2) methanol was added. The tubes were covered with aluminum foil and shaken for $1 \mathrm{~h}$ in a Benchmark Orbi Shaker. After shaking, they were centrifuged at $1792 \mathrm{~g}$ for $15 \mathrm{~min}$ at room temperature with a SIGMA 3-16 KL centrifuge. The supernatant was deposited in $10 \mathrm{ml}$ flask and covered with aluminum foil and kept $4^{\circ} \mathrm{C}$ during the extraction process. Again $4 \mathrm{ml}$ of $70 \%$ acetone was added to the plant material, it was shaken and centrifuged as in the previous step. The supernatant was deposited in the same flask where the supernatant of the first step was deposited, and $10 \mathrm{~mL}$ were gauged with acidified methanol ( $\mathrm{pH} 2)$. Four aliquots of $1.5 \mathrm{~mL}$ of this extraction were placed in Eppendorf tubes and stored at $-20{ }^{\circ} \mathrm{C}$ until quantification.

\subsection{Quantification of total phenols}

Total phenols content were quantified at a micro-scale, as proposed by Arnous et al. (2002), with modifications. A calibration curve was constructed from a standard solution of gallic acid (GA) using concentrations of $0-500 \mu \mathrm{g} / \mathrm{mL}$. Ten $\mu \mathrm{L}$ of the extracts were placed together with $790 \mu \mathrm{L}$ distilled water, $150 \mu \mathrm{L}$ sodium bicarbonate at $20 \%$ and $50 \mu \mathrm{L}$ of Folin reagent. The aliquots were left to stand for $1 \mathrm{~h}$ protected from light. Each sample was loaded in triplicate in plates and absorbance was read at $760 \mathrm{~nm}$ in a Thermo Scientific Multiskan Go 1510 spectrophotometer. The results were expressed in $\mathrm{mg}$ gallic acid per $100 \mathrm{~g}$ of extract (mg GA/100g dry base) for dehydrated plant material and residues and in $\mu \mathrm{g} \mathrm{GA} / \mathrm{mL}$ for infusions.

\subsection{Determination of antioxidants by DPPH and ABTS}

Antioxidant capacity was determined by the ABTS method, following Prior et al. (2005). A trolox calibration curve was used (0 to $0.8 \mathrm{mM})$. An ABTS mother solution $(7 \mathrm{mM})$ and potassium persulfate $(2.4 \mathrm{mM})$ were placed in a precipitation beaker with $10 \mathrm{~mL}$ of distilled water and immediately covered to protect it from light. It was maintained at room temperature for $16 \mathrm{~h}$ in a magnetic stirrer (Dagger Hotplate/Stirrer). Then, was adjusted with $100 \%$ methanol to an absorbance of 0.7. Each sample was loaded in triplicate, depositing $20 \mu \mathrm{L}$ of the sample, plus $200 \mu \mathrm{L}$ ABTS. Absorbance was read at $734 \mathrm{~nm}$ in the Multiskan Go up to $30 \mathrm{~min}$ of reaction. The results in $\mathrm{AC}$ were expressed in $\mu \mathrm{M}$ Trolox equivalents (TE)/g, dry base for dehydrated plant material and residues and in $\mu \mathrm{M} \mathrm{TE} / \mathrm{mL}$ for infusions.

A DPPH solution $(150 \mu \mathrm{M})$ was prepared. A trolox calibration curve was used (0 to $0.8 \mathrm{mM}$ ), and each sample was loaded in triplicate. Twenty $\mu \mathrm{L}$ of sample (blank and the curve) were deposited plus $200 \mu \mathrm{L}$ DPPH. Absorbance was read at $520 \mathrm{~nm}$ in the Multiskan Go, reaction of up to $30 \mathrm{~min}$.

An analysis of variance was performed and afterward a Tukey comparison of means test $(\alpha=0.05)$ with the software Statistical Analysis System version 9.1.3 (SAS Institute, 2007).

\section{Results}

\subsection{Dehydrated plant material}

\section{Total phenol content in dehydrated plant material}

Average values of total phenol contents in dehydrated plant material showed that white tea had the highest TPC with $10813.5 \mathrm{mg} \mathrm{GA} / 100 \mathrm{~g}$ dry base, followed by black tea, green tea and stevia with 6759.5, 5539.9 and $4208.4 \mathrm{mg} \mathrm{GA} / 100 \mathrm{~g}$, respectively. The rest of the plant materials had lower values and were statistically equal (Figure 1a). Independent analysis of each of the materials revealed that white tea WSL was statistically superior with a value of $11750 \mathrm{mg} \mathrm{GA} / 100 \mathrm{~g}$, followed by white tea ASL with $9877 \mathrm{mg} \mathrm{GA} / 100 \mathrm{~g}$. Stevia, black tea and green tea ASL and WSL had intermediate values, and the plant materials ASL and WSL of red tea, lemon grass, chamomile, and spearmint had the lowest values and were statistically equal. No differences were found in averages between plant materials without stevia leaves and plant materials with added stevia leaves (Table 1). 

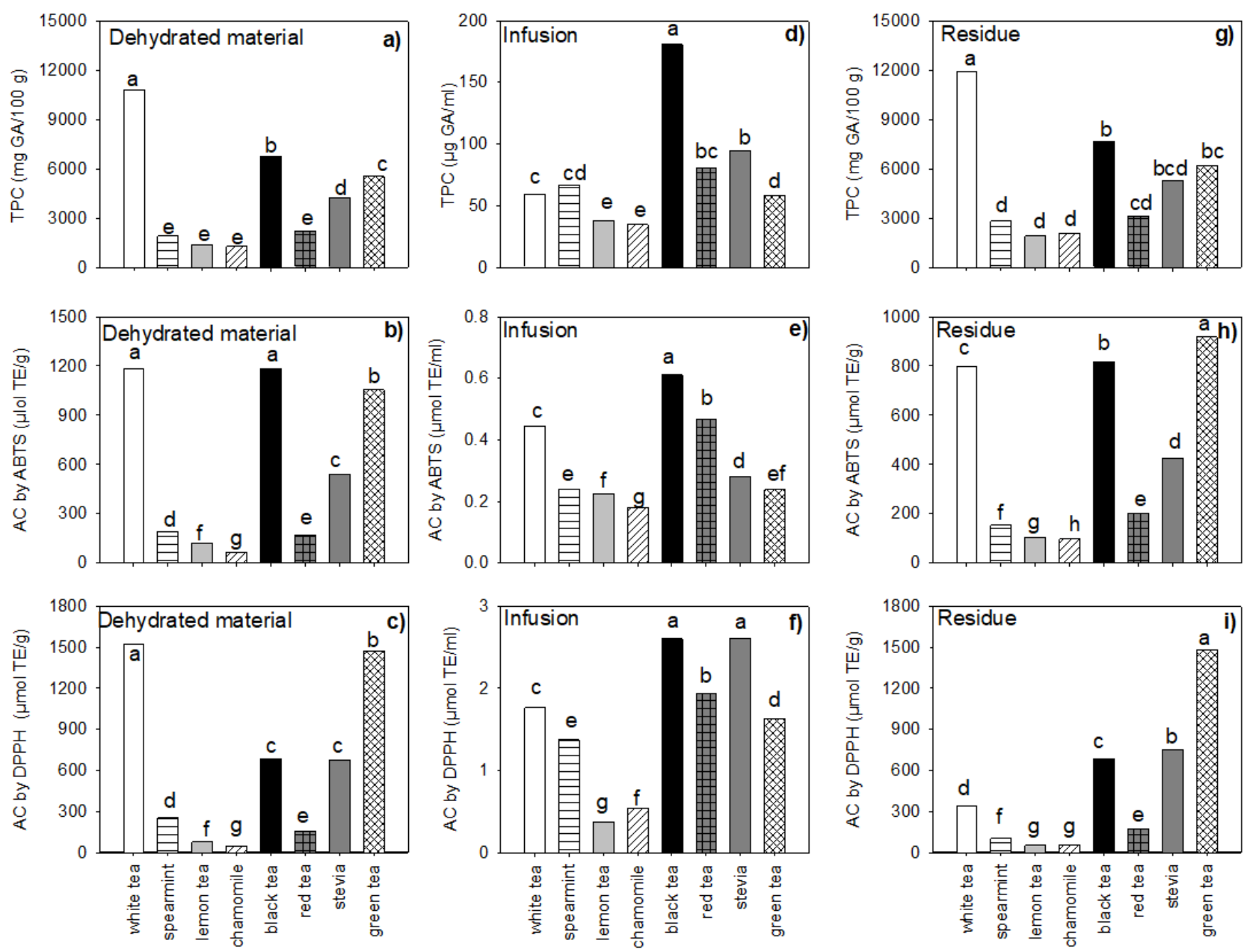

Figure 1. Total Phenol Content (TPC), Antioxidant capacity (AC) by the ABTS and DPPH methods of dehydrated plant material, infusions and residue.

Table 1. Total Phenol Content (TPC, mg GA/100g), Antioxidant capacity (AC, $\mu \mathrm{mol}$ TE/g) by the method ABTS and DPPH of dehydrated plant material and residues without stevia leaf (WSL) and added with stevia leaves (ASL).

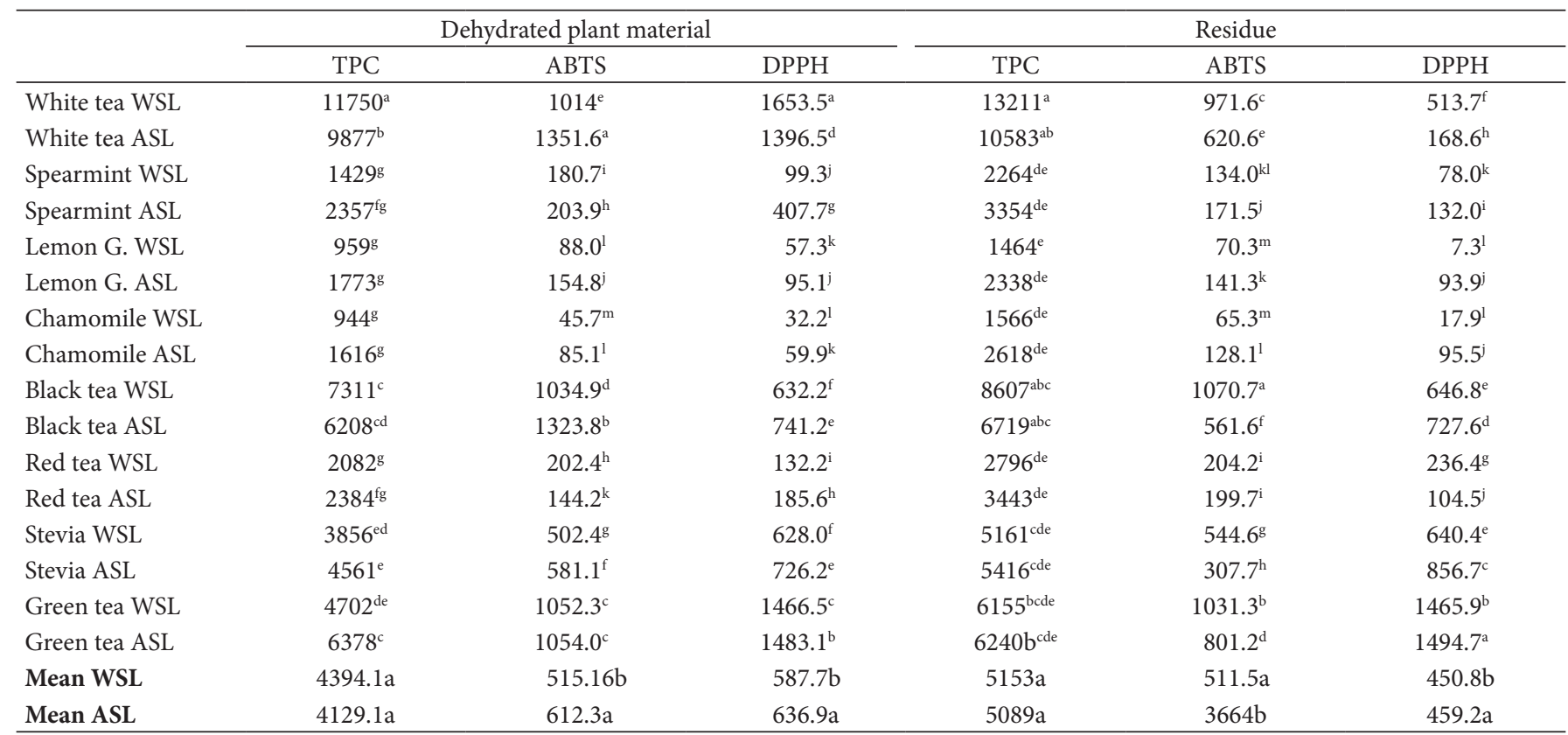

Means with the same letter in column are not significantly different (Tukey, $\mathrm{p}<0.05)$. 


\section{Dehydrated plant material antioxidant capacity by the ABTS method}

Average values obtained by the ABTS method for AC of dehydrated plant materials show that white and black tea are statistically equal and superior (1183.3 and $1179.4 \mu \mathrm{M} \mathrm{TE} / \mathrm{g}$, respectively), followed by green tea with $1053.2 \mu \mathrm{M} \mathrm{TE} / \mathrm{g}$. The lowest values were found in chamomile (Figure 1b). Independent analysis of each plant material revealed that white tea ASL had the highest AC with $1351.6 \mu \mathrm{M} \mathrm{TE} / \mathrm{g}$, followed by black tea ASL with $1323.8 \mu \mathrm{M} \mathrm{TE} / \mathrm{g}$. In contrast, chamomile WSL had the statistically lowest values with $45.7 \mu \mathrm{M} \mathrm{TE} / \mathrm{g}$. Adding stevia leaves to any of the dehydrated plant material increased average $\mathrm{AC}$ values, from $515.16 \mu \mathrm{M} \mathrm{TE} / \mathrm{g}$ to $612.3 \mu \mathrm{M} \mathrm{TE} / \mathrm{g}$ (Table 1).

\section{Antioxidant capacity of dehydrated plant material by the DPPH method}

By the DPPH method, the average AC values of plant material was statistically higher in white tea with a value of $1525.0 \mu \mathrm{M}$ $\mathrm{TE} / \mathrm{g}$, followed by green tea with $1474.7 \mu \mathrm{M} \mathrm{TE} / \mathrm{g}$, while again chamomile had the lowest values with $46.0 \mu \mathrm{M} \mathrm{TE} / \mathrm{g}$ (Figure 1c). Independent analysis of each of dehydrated plant material showed that, white WSL was that with the highest antioxidant capacity with $1653.5 \mu \mathrm{M} \mathrm{TE} / \mathrm{g}$, followed by green tea ASL with a value of $1483.1 \mu \mathrm{M} \mathrm{TE} / \mathrm{g}$; chamomile WSL had the statistically lowest value, $32.2 \mu \mathrm{M} \mathrm{TE} / \mathrm{g}$. Analysis of average values of the group of plant materials WSL compared with plant materials ASL showed that adding stevia leaves resulted in statistically higher values of antioxidant capacity, from 587.7 to $636.9 \mu \mathrm{M} \mathrm{TE} / \mathrm{g}$ (Table 1).

\subsection{Infusions}

Total phenol content in infusions.

Total phenol content was statistically highest in the infusion of black tea, $180.82 \mu \mathrm{g} \mathrm{GAE} / \mathrm{ml}$, followed by stevia, red tea, spearmint, white tea and green tea with values of $94.61,80.20,66.69,59.33$ and $58.48 \mu \mathrm{g} \mathrm{GAE} / \mathrm{ml}$, respectively. The infusions that showed the lowest values were chamomile and lemon grass (Figure 1d). Independent analysis of each of the infusions showed that black tea ASL was statistically superior with $279.17 \mu \mathrm{g} \mathrm{GAE} / \mathrm{ml}$, followed by black tea WSL and PS with values of 142.17 and $121.13, \mu \mathrm{g} \mathrm{GAE} / \mathrm{ml}$, respectively. The infusion of stevia, red tea, green tea, spearmint and white tea with the different sweeteners had intermediate values, and the infusions with the lowest values were of lemon grass and chamomile. TPC averages was statistically higher in the infusions with added stevia leaves with a value of $90.28, \mu \mathrm{g} \mathrm{GAE} / \mathrm{ml}$ than the infusions with processed stevia and without stevia leaves. This means that addition dehydrated stevia leaves increases AC, while adding processed stevia does not contribute to incrementing AC of the infusions (Table 2).

Table 2. Total Phenol Content (TPC), Antioxidant capacity by the ABTS and DPPH methods of infusions without stevia leaf (WSL) and added with stevia leaves (ASL).

\begin{tabular}{|c|c|c|c|}
\hline & TPC ( $\mu \mathrm{g}$ GA/ ml) & $\mathrm{ABTS}(\mu \mathrm{mol} \mathrm{TE} / \mathrm{ml})$ & $\mathrm{DPPH}(\mu \mathrm{mol} \mathrm{TE} / \mathrm{ml})$ \\
\hline White tea WSL & $48.42^{\mathrm{gh}}$ & $0.4808^{\mathrm{d}}$ & $1.7187^{\mathrm{h}}$ \\
\hline White tea ASL & $40.21^{\mathrm{gh}}$ & $0.5335^{\mathrm{c}}$ & $2.1070^{\mathrm{f}}$ \\
\hline White tea PS & $89.37^{\mathrm{de}}$ & $0.3147^{\mathrm{h}}$ & $1.4574^{\mathrm{i}}$ \\
\hline Spearmint WSL & $57.61^{\mathrm{efgh}}$ & $0.2625^{\mathrm{i}}$ & $1.2361^{\mathrm{k}}$ \\
\hline Spearmint ASL & $75.54^{\operatorname{defg}}$ & $0.2350^{\mathrm{jk}}$ & $1.4281^{\mathrm{ij}}$ \\
\hline Spearmint PS & $66.92^{\text {efgh }}$ & $0.218^{\mathrm{klm}}$ & $1.4482^{\mathrm{i}}$ \\
\hline Lemon grass WSL & $35.20^{\mathrm{h}}$ & $0.2377^{\mathrm{jk}}$ & $0.2689^{\mathrm{m}}$ \\
\hline Lemon grass ASL & $38.96^{\mathrm{gh}}$ & $0.2419^{j}$ & $0.6257^{1}$ \\
\hline Lemon grass PS & $39.32^{\mathrm{gh}}$ & $0.1997^{\mathrm{lm}}$ & $0.2224^{\mathrm{m}}$ \\
\hline Chamomile WSL & $30.22^{\mathrm{h}}$ & $0.1972^{\mathrm{m}}$ & $0.1991^{\mathrm{m}}$ \\
\hline Chamomile ASL & $35.24^{\mathrm{h}}$ & $0.2022^{\mathrm{lm}}$ & $0.7541^{\mathrm{nk}}$ \\
\hline Chamomile PS & $38.27^{\mathrm{gh}}$ & $0.1451^{\mathrm{n}}$ & $0.2723^{\mathrm{m}}$ \\
\hline Black tea WSL & $142.17^{\mathrm{b}}$ & $0.7530^{\mathrm{a}}$ & $2.7845^{\mathrm{b}}$ \\
\hline Black tea ASL & $279.17^{\mathrm{a}}$ & $0.6461^{\mathrm{b}}$ & $2.8296^{\mathrm{ab}}$ \\
\hline Black tea PS & $121.13^{\mathrm{bc}}$ & $0.4352^{\mathrm{e}}$ & $2.1807^{\mathrm{f}}$ \\
\hline Red tea WSL & $80.60^{\text {def }}$ & $0.5381^{c}$ & $1.9785^{\mathrm{g}}$ \\
\hline Red tea ASL & $81.34^{\text {def }}$ & $0.4550^{\mathrm{e}}$ & $2.4504^{\mathrm{d}}$ \\
\hline Red tea PS & $78.66^{\text {def }}$ & $0.4076^{\mathrm{f}}$ & $1.3762^{\mathrm{ij}}$ \\
\hline Stevia WSL & $91.77^{\mathrm{def}}$ & $0.2813^{\mathrm{i}}$ & $2.3325^{\mathrm{e}}$ \\
\hline Stevia ASL & $104.97^{\mathrm{cd}}$ & $0.3384^{\mathrm{g}}$ & $2.8382^{\mathrm{ab}}$ \\
\hline Stevia PS & $87.09^{\text {cde }}$ & $0.2219^{\mathrm{jkl}}$ & $2.6453^{\mathrm{c}}$ \\
\hline Green tea WSL & $45.85^{\mathrm{fgh}}$ & $0.2175^{\mathrm{klm}}$ & $0.6597^{1}$ \\
\hline Green tea ASL & $66.80^{\text {efgh }}$ & $0.2300^{\mathrm{jk}}$ & $2.8790^{\mathrm{a}}$ \\
\hline Green tea PS & $62.80^{\text {efgh }}$ & $0.2663^{\mathrm{i}}$ & $1.3485^{j}$ \\
\hline Mean WSL & $66.48^{\mathrm{b}}$ & $0.3710^{\mathrm{a}}$ & $1.3972^{\mathrm{b}}$ \\
\hline Mean ASL & $90.28^{\mathrm{a}}$ & $0.3602^{\mathrm{b}}$ & $1.9890^{\mathrm{a}}$ \\
\hline Mean PS & $72.94^{\mathrm{b}}$ & $0.2762^{c}$ & $1.3689^{\mathrm{b}}$ \\
\hline
\end{tabular}

Means with the same letter in columns are not significantly different (Tukey, $\mathrm{p}<0.05$ ). 


\section{Infusion antioxidant capacity by the ABTS method}

Average antioxidant capacity by the ABTS method was statistically the highest in black tea, $0.6114 \mu \mathrm{M}$ TE/ml, followed by red tea, white tea, stevia, spearmint, green tea, lemon grass and chamomile (Figure 1e). Independently, black tea WSL had the highest statistical value, $0.7530 \mu \mathrm{M} \mathrm{TE} / \mathrm{ml}$, followed by black tea ASL, white tea ASL and white tea WSL with values of $0.6461,0.5335$ and $0.4808 \mu \mathrm{M} \mathrm{TE} / \mathrm{ml}$, respectively. The AC by the ABTS method of the averages of all the infusions without stevia leaves, with added stevia leaves and processed stevia had values of $0.3710,0.3602$ and $0.2762 \mu \mathrm{M} \mathrm{TE} / \mathrm{ml}$, respectively, indicating higher values for infusions without stevia leaves. However, analyzing infusions separately, it can be observed that infusions of white tea, stevia, chamomile, lemon grass and green tea with added dehydrated stevia leaves have higher $\mathrm{AC}$ than the same teas sweetened with processed stevia or without adding stevia leaves. Only black tea, red tea and spearmint have higher $\mathrm{AC}$ without stevia leaves or with processed stevia (Table 2).

\section{Antioxidant capacity of infusions by the DPPH method}

The DPPH method for average AC of WSL, ASL and PS of each infusion resulted in that black tea and stevia were statistically equal and superior to the rest of the teas with values of 2.6053 and $2.5983 \mu \mathrm{M} \mathrm{TE} / \mathrm{ml}$, respectively, followed by red tea, white tea, green tea, spearmint, chamomile and lemon grass with values of $1.9351,1.7611,1.6290,1.3708,0.5422$ and $0.3723 \mu \mathrm{M} \mathrm{TE} / \mathrm{ml}$ respectively (Figure 1f). Analyzed independently, green tea ASL obtained the highest statistical value, $2.8790 \mu \mathrm{M} \mathrm{TE} / \mathrm{ml}$, followed by stevia ASL and black tea ASL, with values of 2.8382 and $2.8296 \mu \mathrm{M} \mathrm{TE} / \mathrm{ml}$, respectively. All the infusions with added dehydrated stevia leaves had higher antioxidant capacity than infusions WSL or PS, except the infusion of spearmint. In general, both ABTS and DPPH methods showed the highest TPC and AC in black tea and the infusions with the lowest values were chamomile and lemon grass. The DPPH method, comparing only averages of the infusions WSL, PS and ASL, showed that AC had the same trend as TPC in that the infusions with added stevia leaves showed higher AC than those to which stevia leaves were not added or those with added processed stevia (Table 2).

\subsection{Residues}

\section{Total phenol content in residues}

Total phenol contents was statistically superior in white tea with $11897 \mathrm{mg}$ GAE/100g, followed by black and green teas with values of 7663 and $6198, \mathrm{mg}$ GAE/100g respectively; the rest of the residues were statistically lower than those mentioned (Figure 1g). The TPC of the residues of white tea

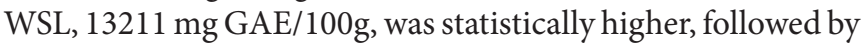
white tea ASL, $10583 \mathrm{mg} \mathrm{GAE} / 100 \mathrm{~g}$. In contrast, lemon grass tea had the lowest value (1464 mg GAE/100g). No differences were found when we compared the average of all the residues without stevia leaves with all the residues with added stevia leaves (Table 1).

\section{Antioxidant capacity of residues by the ABTS method}

Green tea had the statistically highest AC by ABTS with 916.3 $\mu \mathrm{M}$ TE/g, followed by black tea and white tea, with values of 816.2 and $796.1 \mu \mathrm{M} \mathrm{TE} / \mathrm{g}$, respectively, while chamomile again had the lowest values, 96.7 $\mu \mathrm{M} \mathrm{TE} / \mathrm{g}$ (Figure 1h). Individually, black tea residues WSL had the highest AC with $1070.7 \mu \mathrm{M}$ $\mathrm{TE} / \mathrm{g}$, followed by green tea WSL and white tea WSL with values of 1031.3 and $971.6 \mu \mathrm{M} \mathrm{TE} / \mathrm{g}$, respectively. The lowest values, which were statistically equal, were those of lemon grass WSL and chamomile WSL, with values of 64.3 and $70.3 \mu \mathrm{M}$ TE/g respectively. The comparison of all the residues without stevia leaves with all the plant materials with added stevia leaves showed that those to which stevia leaves were not added were statistically superior with a value of $511.5 \mu \mathrm{M}$ TE/g (Table 1).

\section{Antioxidant capacity of residues by the DPPH method}

AC of the residues by the DPPH method was highest in green tea, $1480.2 \mu \mathrm{M}$ TE/g, followed by stevia, with $748.5 \mu \mathrm{M}$ $\mathrm{TE} / \mathrm{g}$, and the residues with the lowest and statistically equal values were those of lemon grass and chamomile with values of 50.6 and $56.7 \mu \mathrm{M} \mathrm{TE} / \mathrm{g}$, respectively (Figure 1i). Analyzing each of the residues independently, green tea ASL had the highest AC, with $1494.7 \mu \mathrm{M}$ TE/g, followed by green tea WSL, with a value of $1465.9 \mu \mathrm{M} \mathrm{TE} / \mathrm{g}$. The statistically lowest values were found in residues of chamomile and lemon grass WSL. The averages of all the residues without stevia leaves compared with all plant materials with added stevia leaves showed that the materials with added stevia leaves were statistically superior with a value of $459.2 \mu \mathrm{M} \mathrm{TE} / \mathrm{g}$, indicating that, in general, adding stevia to dehydrated plant material increases the antioxidant capacity of the residues (Table 1).

\section{Discussion}

\subsection{Plant material}

Dehydrated plant tissue of white tea had the highest average values of both total phenol content (TPC) and antioxidant capacity (AC) by the ABTS and DPPH methods, even though green, black, red and white teas are from the same plant (Camellia sinensis). The results obtained for TPC are attributable to the process and maturity of the teas. White is from young leaf buds, it is the least processed and is not fermented. Green tea is from fresh mature leaves, like black tea, but the difference is that black tea is fermented (Kosińska \& Andlauer, 2014), while red tea undergoes two fermentations. In this respect, Kim et al., (2011) reports that the TPC and AC were higher in leaves of less processed teas, suggesting that fermentation decreases AC and can result in low potential health benefits. Zhao et al. (2011) also reported higher content of phenolic compounds in powdered white tea $(74.7346 \mathrm{mg} / \mathrm{g})$ than in green tea $(27.9767 \mathrm{mg} / \mathrm{g})$ and green Pu-erh $(46.5586 \mathrm{mg} / \mathrm{g})$. Another explanation of why white tea has higher TPC and AC is that shoots and young leaves have higher TPC and AC than mature leaves (Chan et al., 2007).

In our study, we found that dehydrated stevia had average values of $38.56 \mathrm{mg} \mathrm{GAE} / 100 \mathrm{~g}$, which were lower than those reported by González et al. (2014), who studied the stevia 
variety Morita II from a different provenance, finding values of 50-62 $\mathrm{mg} \mathrm{GAE} / \mathrm{g}^{-1}$.

TPC was not different when stevia leaves were added. However, in AC, adding stevia leaves increased by both DPPH and ABTS. This agrees with other authors who report that stevia has considerable AC (Periche et al., 2014) that increases AC of other plant materials when mixed (Benítez \& Pérez, 2016; Shevchenko et al., 2013).

\subsection{Infusions}

Worldwide, the infusions are an important source of phenolic compounds, and represent a class of bioactive molecules that are closely associated with a variety of health benefits (Cleverdon et al., 2018). Our results for TPC in infusions coincide with Gorjanović et al. (2012), who also report that black tea is that with the highest TPC. In contrast, Atoui et al. (2005), (Deetae et al., 2012), Konieczynski et al. (2017) and (Moraes-de-Souza et al., 2008) report higher TPC in green tea than in black tea. Our results are numerically different and lower than those reported by Muñoz-Velázquez et al. (2012). However, the trend is the same since they report values for chamomile of 61.84 to 69.28 , lemon grass 69.91 to 75.66 , spearmint 150.80 to 231.85 , arnica 173.31 , boldo 312.71 and green tea $1628.05 \mu \mathrm{g} \mathrm{GAE} / \mathrm{ml}$. Likewise, Atoui et al. (2005) report lower TPC for chamomile and high for black tea and Chinese green tea (106, 847 and $1216 \mathrm{mg} \mathrm{GAE/cup,} \mathrm{respectively).}$ Moraes-de-Souza et al. (2008) also report high TPC for green and black teas than for chamomile, coinciding with our study. On the other hand, Camargo et al. (2016) report higher TPC in infusions of white tea $(85.36 \mu \mathrm{g} \mathrm{GAE} / \mathrm{mL})$ than in green, red and black teas, with 76, 45.47 and $43.34 \mu \mathrm{g} \mathrm{GAE} / \mathrm{mL}$, respectively. Moraes-de-Souza et al. (2008) and Gorjanović et al. (2012) report that TPC can be different in different studies because of the way teas are prepared (processing of the plant, concentration, time and temperature of the infusion), herb (species, part used, development stage), characteristics of production (soil, climate, stress) and methods of analysis, among other factors.

The stevia infusion had a high TPC in our study, surpassed only by black tea. Other authors, such as Shukla et al. (2012) have also reported high TPC in aqueous and ethanol extracts of stevia, obtaining 56.74 and $61.50 \mathrm{mg} \mathrm{GA} / \mathrm{g}$, respectively. Likewise, Deetae et al. (2012) reports that stevia is outstanding in TPC, like black and green teas, among 18 infusions evaluated. In this respect, Periche et al. (2014) mentions that because stevia is a natural non-caloric sweetener with beneficial properties, considerable antioxidants and amino acids, its consumption as an infusion is increasing. We found that the infusion of black tea was that with the highest AC, according to both ABTS and DPPH. These results agree with Camargo et al. (2016), who also found the highest AC in black tea when compared with red, green and white teas using the same methodologies. In our study, stevia obtained higher average values than black tea and even had higher AC by the DPPH method than green tea. This agrees with Deetae et al. (2012), who conclude that stevia has properties similar to black and green teas. In this respect, Shukla et al. (2012) concludes that stevia is able to eliminate free radicals. Also, Periche et al. (2014) report that it is a source of natural antioxidants that can benefit health.
The results of AC obtained in our study by the DPPH method in chamomile and spearmint infusions are similar to those reported by Muñoz-Velázquez et al. (2012), who report that the $\mathrm{AC}$ of chamomile is $0.52-0.60,0.63-0.70$ for lemon grass, spearmint 1.28-2.04, arnica 1.47, boldo 3.61 , and green tea $4.90 \mu \mathrm{M} \mathrm{TE} / \mathrm{ml}$, although, the values we obtained for green tea were lower. However, in both studies the same tendency was found: chamomile and lemon grass have the lowest values, spearmint intermediate values and green tea the highest values. Moreover, Atoui et al. (2005) report low levels for chamomile $(0.17 \mathrm{TE})$ and high levels for black and green teas ( 0.54 and $0.57 \mathrm{TE}$, respectively). Moraes-de-Souza et al. (2008), however, report that infusions of chamomile, green tea, and black tea have a high capacity for oxidative inhibition.

The high values found in TPC and AC by the DPPH method when stevia leaves were incorporated into the infusions agree with Benítez \& Pérez (2016), who studied the variation in antioxidant capacity and phenolic compounds of aromatic herbs during the process to obtain a filtrate with stevioside as a natural sweetener. Benítez \& Pérez (2016) and Shevchenko et al. (2013) found that aromatic herbs and Camelia sinensis respectively had increased antioxidant capacity when stevia leaves were added. It is important to highlight that the addition of processed powdered stevia does not increase antioxidant capacity or total phenol contents, thus serving only as a sweetener. In contrast, dehydrated stevia leaves, besides sweetening, also increases TPC and AC as evaluated by the DPPH method.

\subsection{Residues}

Although it has been demonstrated that most of the phenolic compounds (80-90\%) are released in the first five minutes, the release time varies among teas. For example, most of the phenolic compounds in green tea are released in the first 2-3 min (Cleverdon et al., 2018). However, our results show clearly that, even after infusion, the residues still contain a large quantity of TPC and AC, and the availability of TPC increases in all of the evaluated materials, making it feasible to reuse the residues for another infusion.

\section{Conclusions}

The addition dehydrated stevia leaves increases AC in dry material and infusions of white tea, lemon grass, chamomile, stevia by both methods, and of spearmint, black tea, red tea, and green tea by DPPH method. But, the addition of commercial processed powdered stevia does not increases AC or TPC in infusions. The infusion process were not enough to deplete the initial contents of AC and TPC once the dry material was used.

\section{References}

Ahmed, S. R., \& Mukta, S. (2017). Review on Stevia rebaudiana as a non-caloric natural sweetener producing plant. Journal of the Sylhet Agricultural University, 4(1), 15-25.

Arnous, A., Makris, D. P., \& Kefalas, P. (2002). Correlation of pigment and flavanol content with antioxidant properties in selected aged regional wines from Greece. Journal of Food Composition and Analysis, 15(6), 655-665. http://dx.doi.org/10.1006/jfca.2002.1070. 
Atoui, A. K., Mansouri, A., Boskou, G., \& Kefalas, P. (2005). Tea and herbal infusions: their antioxidant activity and phenolic profile. Food Chemistry, 89(1), 27-36. http://dx.doi.org/10.1016/j. foodchem.2004.01.075.

Benítez, N. C. J., \& Pérez, A. G. (2016). Capacidad antioxidante y compuestos bioactivos de un filtrante de cinco hierbas aromáticas y esteviosido (Stevia rebaudina B). La Granja. Revista de Ciencias de la Vida, 24, 83-94.

Camargo, L. E. A., Pedroso, L. S., Vendrame, S. C., Mainardes, R. M., \& Khalil, N. M. (2016). Antioxidant and antifungal activities of Camellia sinensis (L.) Kuntze leaves obtained by different forms of production. Brazilian Journal of Biology = Revista Brasileira de Biologia, 76(2), 428-434. http://dx.doi.org/10.1590/1519-6984.18814. PMid:26983085.

Chan, E. W. C., Lim, Y. Y., \& Chew, Y. (2007). Antioxidant activity of Camellia sinensis leaves and tea from a lowland plantation in Malaysia. Food Chemistry, 102(4), 1214-1222. http://dx.doi.org/10.1016/j. foodchem.2006.07.009.

Cleverdon, R., Elhalaby, Y., McAlpine, M., Gittings, W., \& Ward, W. (2018). Total polyphenol content and antioxidant capacity of tea bags: comparison of black, green, red rooibos, chamomile and peppermint over different steep times. Beverages, 4(1), 15. http:// dx.doi.org/10.3390/beverages4010015.

Deetae, P., Parichanon, P., Trakunleewatthana, P., Chanseetis, C., \& Lertsiri, S. (2012). Antioxidant and anti-glycation properties of Thai herbal teas in comparison with conventional teas. Food Chemistry, 133(3), 953-959. http://dx.doi.org/10.1016/j.foodchem.2012.02.012.

Ghaheri, M., Adibrad, E., Safavi, S. M., Kahrizi, D., Soroush, A., Muhammadi, S., Ghorbani, T., Sabzevari, A., Ansarypour, Z., \& Rahmanian, E. (2018). Effects of life cycle and leaves location on gene expression and glycoside biosynthesis pathway in Stevia rebaudiana Bertoni. Cellular and Molecular Biology, 64(2), 17-22. http://dx.doi. org/10.14715/cmb/2018.64.2.4. PMid:29433623.

González, C., Tapia, M. S., Pérez, E., Dornier, M., \& Morel, G. (2014). Caracterización de cultivares de Stevia rebaudiana Bertoni de diferentes procedencias. Bioagro-, 26, 79-88.

Gorjanović, S., Komes, D., Pastor, F. T., Belščak-Cvitanović, A., Pezo, L., Hečimović, I., \& Sužnjević, D. (2012). Antioxidant capacity of teas and herbal infusions: polarographic assessment. Journal of Agricultural and Food Chemistry, 60(38), 9573-9580. http://dx.doi. org/10.1021/jf302375t. PMid:22950743.

Hernández-Saavedra, D., Hernández-Montiel, H. L., Gamboa-Gómez, C. I., Salgado, L. M., \& Reynoso-Camacho, R. (2013). The effect of Mexican herbal infusions on diet-induced insulin resistance. Nutrafoods, 12(2), 55-63. http://dx.doi.org/10.1007/s13749-013-0015-9.

Joseph, D., \& George, J. (2019). Remedial potentials of sweet leaf: a review on Stevia rebaudiana. International Journal of Pharmaceutical Sciences Review and Research, 54(1), 91-95.

Kim, Y., Goodner, K. L., Park, J.-D., Choi, J., \& Talcott, S. T. (2011). Changes in antioxidant phytochemicals and volatile composition of
Camellia sinensis by oxidation during tea fermentation. Food Chemistry, 129(4), 1331-1342. http://dx.doi.org/10.1016/j.foodchem.2011.05.012.

Konieczynski, P., Viapiana, A., \& Wesolowski, M. (2017). Comparison of Infusions from black and green teas (Camellia sinensis L. Kuntze) and erva-mate (Ilex paraguariensis A. St.-Hil.) based on the content of essential elements, secondary metabolites, and antioxidant activity. Food Analytical Methods, 10(9), 3063-3070. http://dx.doi. org/10.1007/s12161-017-0872-8.

Kosińska, A., \& Andlauer, W. (2014). Antioxidant capacity of tea: effect of processing and storage. In V. Preedy (Eds.), Processing and impact on antioxidants in beverages (chap. 12, pp. 109-120). London: Victor R. Preedy.

Moraes-de-Souza, R. A., Oldoni, T. L. C., Regitano-d’Arce, M. A. B., \& Alencar, S. M. (2008). Antioxidant activity and phenolic composition of herbal infusions consumed in Brazil. Food Science and Technology (Campinas), 6, 41-47.

Muñoz-Velázquez, E. E., Rivas-Díaz, K., Loarca-Piña, M. G. F., Mendoza-Díaz, S., Reynoso-Camacho, R., \& Ramos-Gómez, M. (2012). Comparison of phenolic content, antioxidant capacity and anti-inflamatory activity of commercial herbal infusions. Revista Mexicana de Ciencias Agrícolas, 3(3), 481-495. http://dx.doi. org/10.29312/remexca.v3i3.1443.

Periche, A., Koutsidis, G., \& Escriche, I. (2014). Composition of antioxidants and amino acids in stevia leaf infusions. Plant Foods for Human Nutrition (Dordrecht, Netherlands), 69(1), 1-7. http:// dx.doi.org/10.1007/s11130-013-0398-1. PMid:24293005.

Prior, R. L., Wu, X., \& Schaich, K. (2005). Standardized methods for the determination of antioxidant capacity and phenolics in foods and dietary supplements. Journal of Agricultural and Food Chemistry, 53(10), 4290-4302. http://dx.doi.org/10.1021/jf0502698. PMid:15884874.

SAS Institute. (2007). SAS version 9.1.3 for windows. Cary: SAS Istitute, Inc.

Saura-Calixto, F. (1998). Antioxidant dietary fiber product: a new concept and a potential food ingredient. Journal of Agricultural and Food Chemistry, 46(10), 4303-4306. http://dx.doi.org/10.1021/jf9803841.

Shevchenko, Y., Hemmerich, I., Helfert, J., \& Smetanska, I. (2013). Influence of Stevia-additives on antioxidant properties of different green teas. Agro Food Industry Hi-Tech, 24, 22-26.

Shukla, S., Mehta, A., Mehta, P., \& Bajpai, V. K. (2012). Antioxidant ability and total phenolic content of aqueous leaf extract of Stevia rebaudiana Bert. Experimental and Toxicologic Pathology, 64(7-8), 807-811. http://dx.doi.org/10.1016/j.etp.2011.02.002. PMid:21377849.

Wiseman, S. A., Balentine, D. A., \& Frei, B. (1997). Antioxidants in tea. Critical Reviews in Food Science and Nutrition, 37(8), 705-718. http://dx.doi.org/10.1080/10408399709527798. PMid:9447271.

Zhao, Y., Chen, P., Lin, L., Harnly, J. M., Yu, L., \& Li, Z. (2011). Tentative identification, quantitation, and principal component analysis of green pu-erh, green, and white teas using UPLC/DAD/MS. Food Chemistry, 126(3), 1269-1277. http://dx.doi.org/10.1016/j. foodchem.2010.11.055. PMid:25544798. 